\title{
DIFERENCIAÇÃO DE LOTES DE SEMENTES DE JACARANDÁ-DA-BAHIA (Dalbergia nigra (Vell.) Fr.All. ex Benth.) PELO TESTE DE GERMINAÇÃO EM LABORATÓRIO E VIVEIRO ${ }^{1}$
}

\author{
MARCO ANTONIO MARQUES ${ }^{2}$, RINALDO CESAR PAULA ${ }^{3}$ E TERESINHA DE JESUS DELÉO RODRIGUES ${ }^{4}$
}

\begin{abstract}
RESUMO - O desempenho germinativo de sementes de Dalbergia nigra (jacarandá-da-bahia) foi avaliado em laboratório e viveiro, com o objetivo de verificar a eficiência do teste de germinação em laboratório em predizer o comportamento de lotes de sementes em condições de viveiro. Para tanto sementes pertencentes a três lotes (anos de colheita: lote I - 1998, lote II - 1997 e lote III 1994) foram utilizados para determinar os dados biométricos, teor de água, germinação, índice de velocidade e primeira contagem da germinação e porcentagem de plântulas normais em laboratório e emergência, índice de velocidade de emergência e porcentagem de plântulas normais em viveiro. Sementes pertencentes ao lote III apresentaram qualidade inferior aos lotes I e II, tanto em laboratório como em viveiro. Os altos valores do coeficiente de correlação simples entre as características avaliadas nas duas condições, evidenciam a eficiência do teste de germinação em laboratório em predizer o desempenho germinativo de sementes de jacarandá-da-bahia em viveiro.
\end{abstract}

Termos para indexação: Dalbergia nigra, jacarandá-da-bahia, germinação.

\section{DIFERENCIATION OF Dalbergia nigra (Vell.) Fr.All. ex Benth. SEED LOTS BY LABORATORY AND NURSERY GERMINATION TEST}

\begin{abstract}
The germination ability of Dalbergia nigra seeds was evaluated under laboratory and nursery conditions, in order to verify the efficiency of the lab germination test to predict the germination of seed lots of this species under nursery conditions. With this purpose seeds belonging to three seed lots (harvest years: lot I-1998, lot II-1997 and lot III-1994) were used to determine biometric characters, water content, germination, germination speed index, first germination count, percentage of normal seedlings in the laboratory and emergence index and percentage of normal seedlings in the nursery. Seeds belonging to lot III had the worst quality, either in laboratory and in the nursery. The high values of the correlation coefficient, among the characters analysed, in both conditions, show clearly the efficiency of the laboratory germination test to predict the germination ability of Dalbergia nigra seeds under nursery conditions.

Index terms: Dalbergia nigra, jacarandá-da-bahia, germination.
\end{abstract}

\section{INTRODUÇÃO}

O jacarandá-da-bahia (Dalbergia nigra (Vell.) Fr.All. ex Benth.) pertence à família Fabaceae, ocorrendo em Minas Gerais, São Paulo e Mato Grosso do Sul, principalmente no cerrado, possuindo madeira moderadamente dura, pesada, deco-

\footnotetext{
${ }^{1}$ Aceito para publicação em 2002; trabalho realizado com apoio do CNPq. ${ }^{2}$ Eng $^{\circ}$ Agr $^{\circ}$, MSc. em Produção e Tecnologia de Sementes; e-mail: prosbo@ig.com.br.

${ }^{3}$ Eng $^{\circ}$ Florestal, Doutor em Ciências Florestais, Prof. do Depto. Produção
}

rativa e de grande durabilidade natural (Rizzini, 1972). Espécie tardia a clímax, é recomendada para arborização de pastos ou para arborização de culturas; é utilizada, principalmente, na confecção de foleados (capa de painéis) de objetos decorativos e de escritório; empregada para revestimento de móveis, na fabricação de instrumentos musicais e de caixas de

Vegetal, FCAV/UNESP, 14884-900, Jaboticabal-SP; e-mail: rcpaula@fcav.unesp.br

${ }^{4}$ Biológa, PhD., Prof ${ }^{\text {a }}$ do Depto. Biologia Aplicada a Agropecuária, FCAV/ UNESP; e-mail: tdelro@fcav.unesp.br 
pianos, e muito usada na fabricação de móveis de luxo (Carvalho, 1994). É de interesse prático, quando se dispõe de diferentes lotes de sementes, conhecer a qualidade fisiológica intrínseca de cada um. Em se tratando de espécies florestais, grande parte dos testes utilizados para determinar a qualidade fisiológica de lotes de sementes foram desenvolvidos a partir da utilização de sementes de espécies agrícolas, com alto grau de domesticação e melhoramento. Muitas vezes o uso destes testes não têm o adequado ajuste de metodologia, de forma que os resultados obtidos podem não corresponder à verdadeira qualidade fisiológica dos lotes de sementes avaliados.

Neste sentido, o presente trabalho teve como objetivo verificar o desempenho germinativo de três lotes de sementes de Dalbergia nigra Fr. Allem (jacarandá-da-bahia), em laboratório e viveiro, e correlacionar os resultados obtidos nestas duas condições.

\section{MATERIAL E MÉTODOS}

Foram utilizadas sementes de Dalbergia nigra (Vell.) Fr. All. ex Benth. (jacarandá-da-bahia) pertencentes a três lotes (anos de colheita: lote I-1998, lote II-1997 e lote III-1994). Os lotes apresentavam idades e períodos de armazenamento diferentes e foram obtidos junto ao Laboratório de Análises de Sementes Florestais da Universidade Federal de Viçosa, Viçosa-MG

Após colhidas, as sementes foram retiradas manualmente dos frutos, eliminando-se as sementes chochas e danificadas. Depois foram armazenadas em tamboretes de fibra de madeira, em câmara fria $\left(5^{\circ} \mathrm{C}\right.$ e $85 \pm 5 \%$ de umidade relativa $)$ até fevereiro de 2000, quando foram enviadas para a Faculdade de Ciências Agrárias e Veterinárias (FCAV/UNESP), Campus de Jaboticabal e encaminhadas ao Departamento de Biologia Aplicada à Agropecuária. Foram retiradas amostras de sementes de cada um dos lotes para as seguintes determinações: dados biométricos - determinou-se o comprimento, largura, espessura e peso de 1000 sementes, em 10 repetições de 100 sementes. Os dados foram expressos pela média, desvio padrão e coeficiente de variação (Gomes, 1987 e Banzatto \& Kronka, 1992); teor de água - foi determinado pelo método da estufa a $105 \pm 3^{\circ} \mathrm{C}$ por 24 horas (Brasil, 1992), utilizando-se três repetições de 100 sementes; porcentagem e índice de velocidade de germinação - o teste foi realizado em caixas plásticas de germinação $(11 \times 11 \mathrm{~cm})$, desinfetadas com hipoclorito de sódio a 5\% e revestidas com duas folhas de papel para germinação. Todo o material, exceto as sementes e as caixas, foi autoclavado a $120^{\circ} \mathrm{C}$ por 20 minutos. $\mathrm{O}$ substrato foi umedecido com solução de nistatina a $0,2 \%$. Foram utilizadas quatro repetições de 25 sementes e o experimento foi conduzido em germinador vertical tipo BOD, a $25^{\circ} \mathrm{C}$ constantes e fotoperíodo de oito horas. As contagens do número de sementes germinadas foram realizadas diariamente, sempre no mesmo horário, considerando-se como critério de germinação a protrusão da radícula $(2 \mathrm{~mm})$. Ao final do teste (11 dias) computou-se, também, a porcentagem de plântulas normais, ou seja, aquelas que apresentavam todas as estruturas essenciais perfeitas (Oliveira, 1993). Os dados obtidos foram expressos em porcentagem final de germinação $(\mathrm{G})$, porcentagem de plântulas normais (PNL) e índice de velocidade de germinação, determinado segundo Maguire (1962); primeira contagem da germinação - foi avaliada juntamente com o desenvolvimento do teste de germinação, sendo avaliada no sétimo dia após a instalação do teste; emergência, índice de velocidade de emergência e porcentagem de plântulas normais em viveiro - para esse estudo foi utilizado como substrato uma mistura à base de composto orgânico, casca de arroz carbonizada e terra de subsolo (na proporção de $6: 3: 1, \mathrm{v} / \mathrm{v}$ ) e as sementes foram colocadas para germinar em casa de vegetação, com $50 \%$ de sombreamento e irrigação intermitente. A semeadura foi realizada em tubetes de plástico rígido $\mathrm{com} 50 \mathrm{~cm}^{3}$ de substrato, à profundidade aproximada de $1,0 \mathrm{~cm}$. A avaliação da emergência das plântulas foi realizada até sua estabilização, o que ocorreu com 23 dias. Avaliou-se a porcentagem final de emergência (E), a porcentagem de plântulas normais (PNV) e o índice de velocidade de emergência de plântulas (IVE), de acordo com Maguire (1962). Considerou-se como plântulas normais aquelas com todas as estruturas essenciais perfeitas (Oliveira, 1993). Durante o período experimental em viveiro, a temperatura média ambiental foi de $22,4^{\circ} \mathrm{C}$, a umidade relativa do ar de $73,5 \%$, a temperatura máxima de $29,4^{\circ} \mathrm{C}$ e a mínima de $17,1^{\circ} \mathrm{C}$.

$\mathrm{O}$ delineamento estatístico utilizado foi o inteiramente casualizado com três tratamentos (três lotes) e quatro repetições de 25 sementes. Os dados foram analisados estatisticamente sem transformação e as médias comparadas pelo teste Tukey, a $1 \%$ de probabilidade. Paralelamente, procedeu-se ao cálculo do coeficiente de correlação de Pearson entre os dados de laboratório e viveiro, a $1 \%$ de probabilidade pelo teste t.

\section{RESULTADOS E DISCUSSÃO}

Para o peso de mil sementes não houve grande variação entre os lotes estudados (Tabela 1). No lote I, mil sementes 
TABELA 1. Dados referentes ao tamanho de sementes de jacarandá-da-bahia.

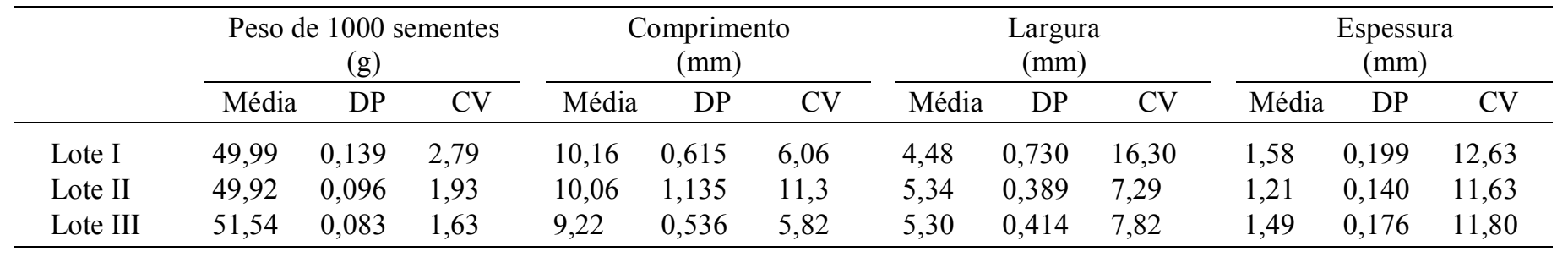

$\mathbf{D P}=$ desvio-padrão; $\mathbf{C V}=$ coeficiente de variação (\%).

pesaram 49,99g, o que corresponde a 20.004 sementes por quilograma. Para o lote II, o número de sementes por quilograma foi de 20.032 e para o lote III este número foi de 19.402 sementes. Estes valores são superiores àquele citado por Davide et al. (1995), que corresponde a 17.300 sementes.

O comprimento médio das sementes foi de $10,16 \mathrm{~mm}$ para o lote I, $10,06 \mathrm{~mm}$ para o lote II e $9,22 \mathrm{~mm}$ para o lote III, correspondendo a uma variação de $9,25 \%$ entre o lote de maior e o de menor comprimento de sementes.

A largura das sementes foi de $4,48 \mathrm{~mm}, 5,34 \mathrm{~mm}$ e $5,30 \mathrm{~mm}$, respectivamente, para as sementes pertencentes aos lotes I, II e III. A diferença entre os lotes com maior e menor largura das sementes foi de 16,10\%. Paoli (1991) observou para sementes da mesma espécie, em média $11,0 \mathrm{~mm}$ de comprimento por $5,0 \mathrm{~mm}$ de largura.

Para espessura das sementes a diferença entre os lotes com maior (lote I) e menor espessura (lote II) foi de $23,42 \%$. Esta característica foi a que apresentou maior variabilidade entre as sementes nos três lotes, conforme pode ser verificado pelos valores dos coeficientes da variação (Tabela 1).

De acordo com Piña-Rodrigues \& Aguiar (1993), o tamanho e o peso das sementes de determinada espécie são características extremamente plásticas, variando de local para local, de ano para ano e entre e dentro de indivíduos.

As sementes pertencentes ao lote II apresentaram maiores valores de primeira contagem da germinação e de índice de velocidade de germinação, diferindo significativamente dos demais lotes. Para estas duas características avaliadas o lote III apresentou os piores resultados, isso também se deve ao fato desse lote ser de 1994, enquanto os outros dois (I e II) eram de 1998 e 1997. Para a germinação e plântulas normais, os lotes I e II foram superiores ao lote III (Tabela 2).

As três características avaliadas no teste de viveiro, discriminaram da mesma forma os três lotes, como sendo os lotes I e II superiores ao lote III, coincidindo, assim, com os resultados obtidos em laboratório para germinação e plântulas normais (Tabela 2).

Os valores dos coeficientes de correlação entre pares de características avaliadas em laboratório foram todos elevados, indicando boa correlação entre as características estudadas (Tabela 3). Os maiores valores foram observados entre G x PNL $(r=0,98), G$ x IVG $(r=0,99)$ e PC x IVG $(r=0,97)$. Entre as características avaliadas em condições de viveiro, também houve altas correlações. Também foram ob-

TABELA 2. Germinação em laboratório e em viveiro de sementes de jacarandá-da-bahia.

\begin{tabular}{|c|c|c|c|c|c|c|c|}
\hline \multirow{2}{*}{ Lotes } & \multicolumn{4}{|c|}{ Laboratório } & \multicolumn{3}{|c|}{ Viveiro } \\
\hline & PC (\%) & $\mathrm{G}(\%)$ & PNL (\%) & IVG & E (\%) & PNV (\%) & IVE \\
\hline Lote I & $61 \mathrm{~b}$ & $82 \mathrm{a}$ & $70 a$ & $6,8 \mathrm{~b}$ & $61 \mathrm{a}$ & $38 \mathrm{a}$ & $1,20 \mathrm{a}$ \\
\hline Lote II & $80 a$ & $91 \mathrm{a}$ & $74 a$ & $8,6 a$ & $71 \mathrm{a}$ & $43 a$ & $1,60 \mathrm{a}$ \\
\hline Lote III & $11 \mathrm{c}$ & $17 \mathrm{~b}$ & $7 \mathrm{~b}$ & $1,2 \mathrm{c}$ & $3 \mathrm{~b}$ & $1 \mathrm{~b}$ & $0,04 \mathrm{~b}$ \\
\hline $\mathrm{F} \mathrm{p/} \mathrm{lotes}$ & $57,09^{* *}$ & $292,00 * *$ & $149,92 * *$ & $346,09 * *$ & $88,55^{* *}$ & $52,63 * *$ & $26,91 * *$ \\
\hline CV (\%) & 18,81 & 7,52 & 12,33 & 7,44 & 17,34 & 23,14 & 32,86 \\
\hline Média & 50 & 63 & 50 & 6 & 45 & 27 & 1 \\
\hline
\end{tabular}

$* *$ = Valor significativo a $1 \%$ pelo teste $\mathrm{F}$.

Médias seguidas pela mesma letra, na coluna, não diferem entre si pelo teste de Tukey, a 1\%.

$\mathbf{P C}=$ Primeira contagem da germinação; $\mathbf{G}=$ Germinação; $\mathbf{P N L}=$ Plântulas normais em laboratório; $\mathbf{I V G}=$ Índice de velocidade de germinação; $\mathbf{E}=$ Emergência das plântulas; $\mathbf{P N V}=$ Plântulas normais em viveiro; IVE = Índice de velocidade de emergência. 
servados valores elevados do coeficiente de correlação entre as avaliações de laboratório e de viveiro (Tabela 3), sendo, o maior valor observado entre PNL x E $(r=0,96)$ e o menor entre PC x PNV $(r=0,87)$. Estes resultados evidenciam a boa associação entre os resultados obtidos em condições de laboratório e viveiro para a espécie em estudo.

\section{CONCLUSÕES}

- As sementes de jacarandá-da-bahia dos lotes I e II apresentaram qualidade superior as do lote III;

- houve alta correlação entre os resultados obtidos em laboratório e viveiro;

- os testes de laboratório discriminam eficientemente os lotes em relação ao seu desempenho em viveiro.

\section{REFERÊNCIAS}

BANZATTO, D.A. \& KRONKA, S.N. Experimentação agrícola. 2.ed. Jaboticabal: FUNEP, 1995. 246p.

BRASIL. Ministério da Agricultura e Reforma Agrária. Regras para análise de sementes. Brasília: SNDA/DNDV/CLAV, 1992. $365 \mathrm{p}$.

CARVALHO, P.E.R. Espécies florestais brasileiras: recomendações silviculturais, potencialidades e uso da madeira. Colombo: EMBRAPA/CNPF, 1994. p.213-218.

DAVIDE, A.C.; FARIA, J.M.R. \& BOTELHO, S.A. Propagação de espécies florestais. Belo Horizonte: CEMIG/UFLA/FAEPE, 1995. 40p.

GOMES, F.P. Curso de estatística experimental. Piracicaba: Nobel, 1987. $467 \mathrm{p}$
TABELA 3. Coeficientes de correlação simples entre as características avaliadas no laboratório e no viveiro para sementes de jacarandá-da-bahia.

\begin{tabular}{lcccccc} 
& PC & PNL & IVG & E & PNV & IVE \\
G & $0,94 * *$ & $0,98^{* *}$ & $0,99 * *$ & $0,96 * *$ & $0,95^{* *}$ & $0,94 * *$ \\
PC & & $0,95 * *$ & $0,97 * *$ & $0,92^{* *}$ & $0,87 * *$ & $0,87 * *$ \\
PNL & & & $0,97 * *$ & $0,96 * *$ & $0,97^{* *}$ & $0,91 * *$ \\
IVG & & & & $0,96 * *$ & $0,93 * *$ & $0,93 * *$ \\
E & & & & & $0,96 * *$ & $0,96 * *$ \\
PNV & & & & & & $0,97 * *$ \\
\hline
\end{tabular}

$* *=$ Valor significativo a $1 \%$ pelo teste $\mathrm{t}$.

$=$ Germinação em laboratório; $\mathbf{P C}=$ Primeira contagem de germinação em laboratório; $\mathbf{P N L}=$ Plântulas normais em laboratório; IVG = Índice de velocidade de germinação em laboratório; $\mathbf{E}$ =Emergência das plântulas em viveiro; $\mathbf{P N V}=$ Plântulas normais em viveiro; IVE = Índice de elocidade de emergência em viveiro.
MAGUIRE, J.D. Speed of germination - aid in selection and evaluation for seedling emergence and vigor. Crop Science, Madison, v.2, n.1, p.176-177, 1962.

OLIVEIRA, E.C. Morfologia de plântulas florestais. In: AGUIAR, I.B.; PIÑA-RODRIGUES, F.C.M. \& FIGLIOLIA, M.B. (coords.). Sementes florestais tropicais. Brasília: ABRATES, 1993. p.175-213.

PAOLI, A.A.S. Morfo-anatomia e aspectos da germinação das sementes de Dalbergia nigra (Vell.) Fr.All. ex Benth. (Leguminosae-Papilionoideae). Ecossistema, Espirito Santo do Pinhal, v.16, p.28-36, 1991.

PIÑA-RODRIGUES, F.C.M. \& AGUIAR, I.B. Maturação e dispersão de sementes. In: AGUIAR, I.B.; PIÑA-RODRIGUES, F.C.M. \& FIGLIOLIA, M.B. (coords.). Sementes florestais tropicais. Brasília: ABRATES, 1993. p.215-274.

RIZZINI, C.T. Árvores e madeiras úteis do Brasil: manual de dendrologia brasileira. São Paulo: Editora da USP, 1972. $294 p$

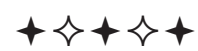

